Supplement of Arch. Anim. Breed., 61, 433-439, 2018

https://doi.org/10.5194/aab-61-433-2018-supplement

(c) Author(s) 2018. This work is distributed under

the Creative Commons Attribution 4.0 License.

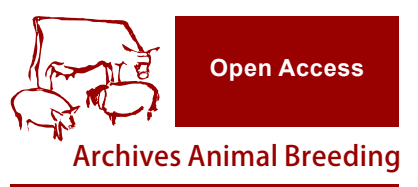

(c) (i)

Supplement of

\title{
Effects of polymorphisms in CAPN1 and CAST genes on meat tenderness of Chinese Simmental cattle
}

Xiaomei Sun et al.

Correspondence to: Zhangping Yang (yzp@yzu.edu.cn)

The copyright of individual parts of the supplement might differ from the CC BY 4.0 License. 
Table S1. The primers used for PCR-SSCP analysis of bovine CAPN1 and CAST genes

\begin{tabular}{|c|c|c|c|c|c|c|}
\hline $\begin{array}{l}\text { Primer } \\
\text { List }\end{array}$ & Gene & Position & Primer sequence $\left(5^{\prime}-3^{\prime}\right)$ & $\begin{array}{l}\text { Accession } \\
\text { Number }\end{array}$ & $\begin{array}{l}\text { Size } \\
(\mathrm{bp})\end{array}$ & $\mathrm{T}_{\mathrm{m}}\left({ }^{\circ} \mathrm{C}\right)$ \\
\hline $\mathrm{P} 1$ & CAPN1 & Exon 1 & $\begin{array}{l}\text { F:GGCCGAGGAGATACCGTGAA } \\
\text { R:TTACCTGGGGGAGGAGTGTTG }\end{array}$ & AF248054 & 222 & 61.2 \\
\hline $\mathrm{P} 2$ & CAPN1 & Exon2 & $\begin{array}{l}\text { F:CCTTCCTCGTTCCTTGTGCTA } \\
\text { R:CCCAAGCCTGTGGTTTCC }\end{array}$ & AF248054 & 246 & 58.6 \\
\hline P3 & CAPN1 & Exon3 & $\begin{array}{l}\text { F:TGACTTTGTGCTGCGTTTCT } \\
\text { R:AGACCAAGACACAGGACACCC }\end{array}$ & AF248054 & 247 & 58.6 \\
\hline $\mathrm{P} 4$ & CAPN1 & Exon4 & $\begin{array}{l}\text { F:CAATCTCCCCGACGAGGT } \\
\text { R:CCGGGTGATCCAGGTAAACAG }\end{array}$ & AF248054 & 244 & 58.6 \\
\hline P5 & CAPN1 & Exon 5 & $\begin{array}{l}\text { F:ATAGAGGCTGGGCAGGTCAGT } \\
\text { R:AACCAGGATGCCCAGTCG }\end{array}$ & AF248054 & 238 & 55 \\
\hline P6 & CAPN1 & Exon 6 & $\begin{array}{l}\text { F:GGATCTCTGGTTTCTGAGGGT } \\
\text { R:AGGGCATAGAGAGCAGTC }\end{array}$ & AF248054 & 229 & 53.2 \\
\hline P7 & CAST & Exon9 & $\begin{array}{l}\text { F: TGGGGTGTATGCGTGTTT } \\
\text { R: } \text { TCCAATCCTGCACTCCTG }\end{array}$ & AF158246 & 257 & 54.2 \\
\hline
\end{tabular}

Note: Tm, annealing temperature 